\title{
The Effects of Laser Peening and Shot Peening on Mechanical Properties in Friction Stir Welded 7075-T7351 Aluminum
}

\author{
Omar Hatamleh ${ }^{1}$ \\ Structures \& Dynamics Branch, NASA-Johnson Space Center, Houston, Texas 77058
}

\begin{abstract}
Peening techniques like laser peening and shot peening were used to modify the surface of friction stir welded 7075-T7351 Aluminum Alloy specimens. The tensile coupons were machined such as the loading was applied in a direction perpendicular to the weld direction. The peening effects on the global and local mechanical properties through the different regions of the weld were characterized and assessed. The surface hardness levels resulting from various peening techniques were also investigated for both sides of the welds. Shot peening resulted in an increase to surface hardness levels, but no improvement was noticed on the mechanical properties. In contrast, mechanical properties were improved by laser peening when compared to the unpeened material.
\end{abstract}

Keywords: friction stir welding, laser peening, shot peening, mechanical properties

\section{Introduction}

Since its invention by the Welding Institute in 1991 [1], friction stir welding (FSW) has emerged as a promising solid state process with encouraging results. FSW is considered a better technique than fusion welding for many aluminum alloys, and it surpasses other fusion welding processes in terms of the lack of solidification cracks, and

${ }^{1}$ Corresponding author. Tel: (281) 483-0286; Fax: (281) 244-5918

Email: omar.hatamleh-1@nasa.gov 
porosity. This is particularly important when used on high strength aerospace aluminum alloys that are generally difficult to weld.

The modified microstructure resulting from FSW is asymmetric about the weld centerline [2]. This is due to the advancing and retreating sides of the weld corresponding to maximum and minimum relative velocities between the tool and workpiece [3]. The FSW consists of a nugget, or the stirred zone, the thermo-mechanical affected zone (TMAZ), and a heat affected zone (HAZ).

The use of FSW is expanding rapidly and is resulting in welded joints being used in critical load bearing structures. Therefore, it is important to investigate methods to improve the weakened mechanical properties produced from the welding process for components welded using FSW. Peening techniques like laser and shot peening has been reported to enhance mechanical properties in fusion welds $[4,5]$, however none of the investigations in literature assessed laser peening effects on the various regions of the FSW.

In this study, the laser peening, shot peening, and a combination of both was used to introduce compressive residual stresses into FSW AA 7075-T7351. The influence of the different peening techniques on mechanical properties and hardness levels on both sides of the FSW specimens were characterized and assessed. 


\section{Experimental Procedures}

The 7075 aluminum alloy (AA) was used in this investigation. This high strength precipitation-hardened aluminum alloy is used extensively in aerospace applications. The base metal was supplied in a T651 temper which is solution heat treated and artificially aged, then stress relieved by stretching. The 7075-T651 was supplied as a $6.35 \mathrm{~mm}$ thick plate with an ultimate and yield strength of $601 \mathrm{MPa}$, and $534 \mathrm{MPa}$ respectively and an elongation of $11 \%$.

The FSW specimens for this investigation were made at the NASA- Johnson Space Center using a 5-axis milling machine, and were welded in a butt-weld configuration along rolling direction. The tool rotation was set at $350 \mathrm{rpm}$ in the counterclockwise direction, and the traverse speed was set at a rate of $2.54 \mathrm{~cm} / \mathrm{min}$ stirring the interface and producing a solid-state weld. The FSW panels were $122 \mathrm{~cm} \mathrm{x} 40$ $\mathrm{cm} \times 0.65 \mathrm{~cm}$. The welded plates were heat treated to prevent the material from continuing to age at room temperature $[6,7]$. Following the welding process, the welded plates were aged from the T651 condition to the T7351 condition in accordance with the SAE AMS-H-6088 requirements.

The FSW plates were inspected using radiographic and penetrant inspections after the heat treatment process, with no defects being detected. Bending tests using strips specimens with dimensions of $17.8 \mathrm{~cm} \times 2.54 \mathrm{~cm}$ were also performed. Both the root and the crown sides of the weld were tested to evaluate the quality of the weld. The samples were inspected visually afterward with no crack indications revealed. 
Laser peening (LP), as shown in Figure 1, is a technology that introduces a state of residual compressive stresses with the ability to develop deep, high compressive stresses in the areas treated. The LP process uses high energy laser pulses (several $\mathrm{GW} / \mathrm{cm}^{2}$ ) fired at the surface of a metal coated with an ablative film, and covered with a transparent layer (usually water). As the laser beam passes through the transparent layer and hits the surface of the material, a thin layer of the ablative layer is vaporized. The vapor continues to absorb the remaining laser energy and is heated and ionized into plasma. The rapidly expanding plasma is trapped between the sample and the transparent layer, creating a high surface pressure, which propagates into the material as a shock wave [8].

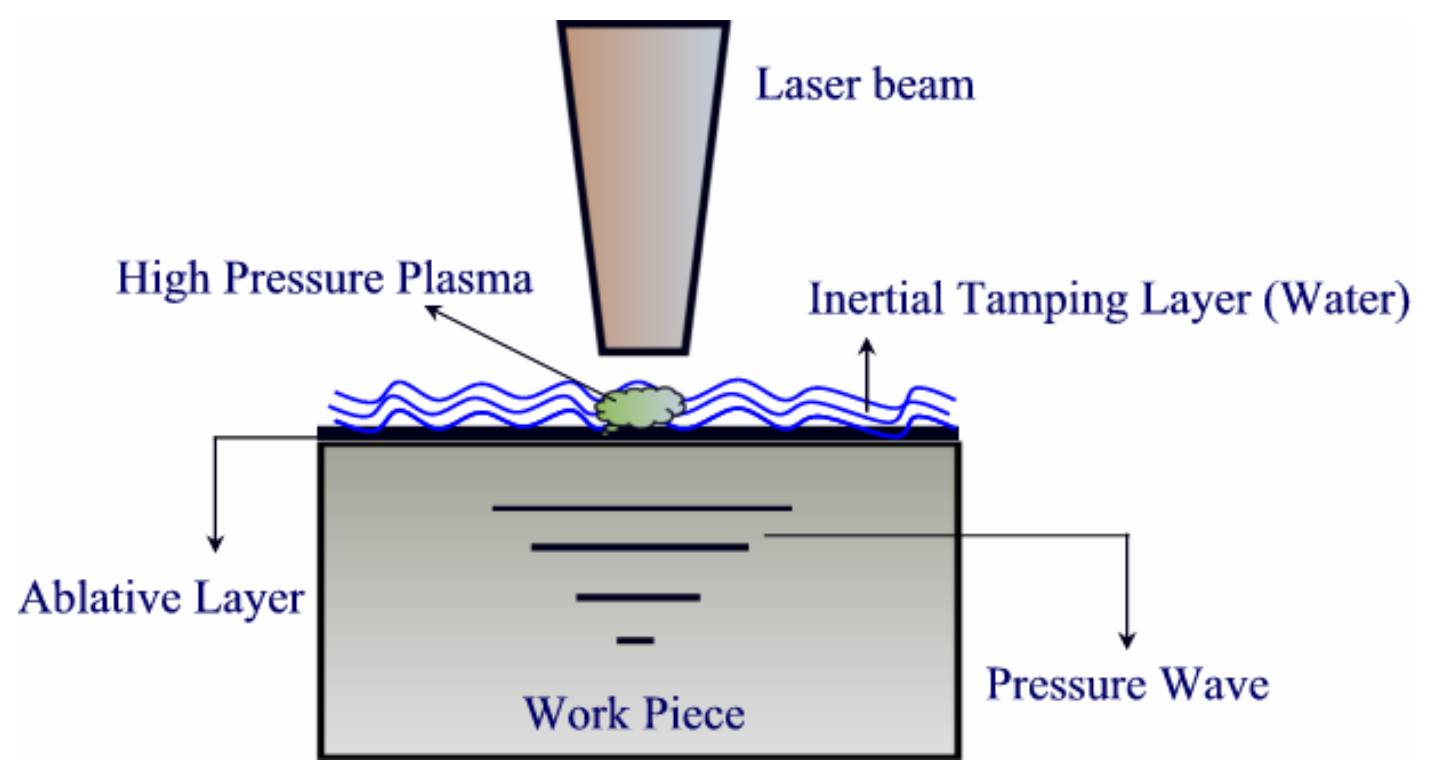

Figure 1 Laser peening process

When the peak pressure of the shock wave is greater than the dynamic yield strength of the material, it produces extensive plastic deformation in the metal. The 
actual depths of the LP induced stresses will vary depending on the type, intensity of the processing conditions chosen and the material properties [9].

The laser peening was performed at the Metal Improvement Company in Livermore California. The surfaces of the specimens intended for peening were covered with an aluminum tape $0.22 \mathrm{~mm}$ thick. The aluminum tape was replaced between layers of peening. The tamping layer consisted of an approximately $1 \mathrm{~mm}$ thick laminar layer of flowing water. Some laser peened specimens were peened using a single layer $(100 \%)$, and others using a triple (300\%) layers. A square laser spot size of $4.72 \times 4.72 \mathrm{~mm}^{2}$ was used using a laser power density of $5 \mathrm{GW} / \mathrm{cm}^{2}$ and $18 \mathrm{~ns}$ duration. The spots within a layer were overlapped 3\%. Peening between layers had an off-set of 50\% in each direction. A peening frequency of $2.7 \mathrm{~Hz}$ and a 1 micron wavelength laser was employed. The peening was applied on the total length of the gauge section on both faces and sides of the specimens.

The shot peening process was optimized using "Peenstress" a software developed at Metal Improvement Company. Based on this evaluation, the samples were shot-peened with 0.0234" glass beads, with an Almen intensity of $0.008-0.012 \mathrm{~A}$ and a $200 \%$ coverage rate. To investigate the effects of combining laser and shot peening on the mechanical properties, some of the laser coupons that were processed with a single layer of laser were also shot peened.

Tensile testing was performed at room temperature on a $200 \mathrm{KN}$ servo-hydraulic universal testing machine using a constant crosshead speed of $0.1 \mathrm{~mm} / \mathrm{min}$. The transverse tensile specimens consisted of conventional dog bone coupons and were $20 \mathrm{~cm}$ long with a gage length of $8.5 \mathrm{~cm}$ and a gage width of $1.27 \mathrm{~cm}$ in accordance with ASTM E8 standard. The coupons were oriented such that the weld was in the center of the 
specimen and the load was applied perpendicular to the weld direction. Prior to the peening process, the specimens were milled on the top side of the weld removing about $0.4 \mathrm{~mm}$ of material. Mechanical properties obtained in the transverse tensile test of the FSW weld generally represent the weakest region of the weld. In that configuration, the elongation constitutes an average strain over the whole gage length which includes the different weld region. This in return does not provide an insight into the correlation between the intrinsic tensile properties and localized microstructure [10]. Therefore the intrinsic tensile properties for various locations across the weld zone were also characterized by a tensile test using a set of strain gauges as illustrated in Figure 2. The local strain data was mapped to the corresponding global stress levels by assuming that the transversely loaded FSW specimens were considered a composite material loaded in an iso-stress configuration [9]. Using this assumption, local constitutive stress-strain relationships were obtained. The accuracy of the measured tensile properties is therefore determined by the degree of non-homogeneity and residual stress levels at all cross sections to which the load is applied.

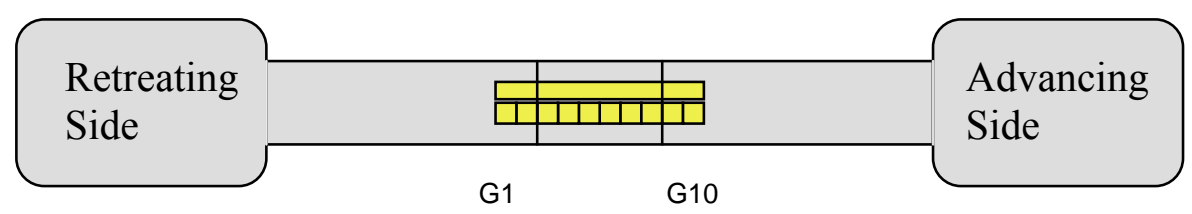

Figure 2 Tensile test coupon used for testing 


\section{Results and Discussion}

\subsection{Weld microstructure}

The Microstructure of the weld zone was assessed using digital, optical, and scanning electron microscopes. The specimen used for metallographic investigation was cut and sectioned in a direction normal to the welding direction, and then subjected to several successive steps of grinding and polishing. After that, the specimen was etched using a Keller's reagent that consists of $190 \mathrm{ml}$ of $\mathrm{H} 2 \mathrm{O}, 5 \mathrm{ml}$ of $\mathrm{HNO} 3,2 \mathrm{ml}$ of $\mathrm{HF}$, and $3 \mathrm{ml}$ of HCL.

A weld cross section showing different regions of the weld is shown in Figure 3. The cross section revealed the classical formation of the elliptical onion rings structure in the center of the weld. These rings were caused by the rotational flow of the welding tool, and have been attributed to the incremental advance of the tool per revolution [11]. The FSW sample showed no evidence of porosity, or other kinds of defects. The weld nugget seems wider on the crown region of the weld because the upper surface contact with the tool shoulder.

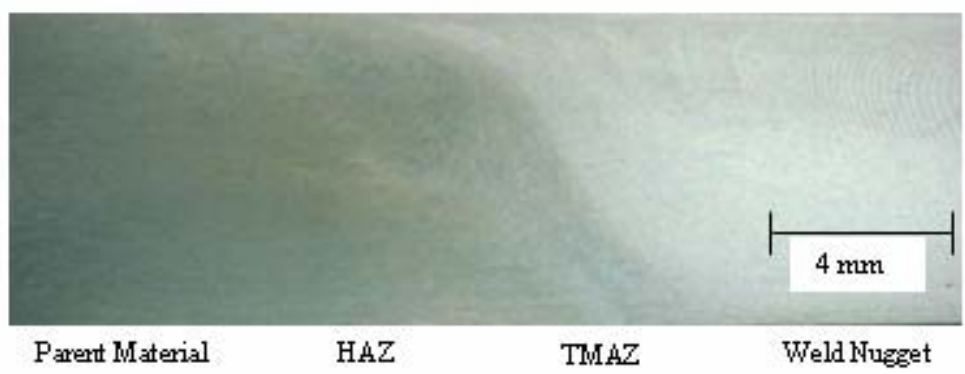

Figure 3 A Cross section of the welded specimen

Another cross section of the weld (Figure 4) illustrates the transition from the nugget- TMAZ-HAZ microstructure on the retreating area of the weld. The grain 
structure at the nugget is fine and equiaxed grains typical of a recrystallized structure. The grain sizes in this region are of the order of 5-12 $\mu \mathrm{m}$, and are significantly smaller than the parent material grain due to the higher temperature and extensive plastic deformation. The grain structure at the TMAZ region is elongated, with some considerable distortions that may be attributed to mechanical action from the welding tool. The HAZ is unaffected by the mechanical effects from the tool, and has a grain structure that resembles the parent material grain structure. Even though the grain size in this region resemble the base material, previous work by [12] showed the strengthening precipitates in this region have grown in size and were several times larger than in the parent material

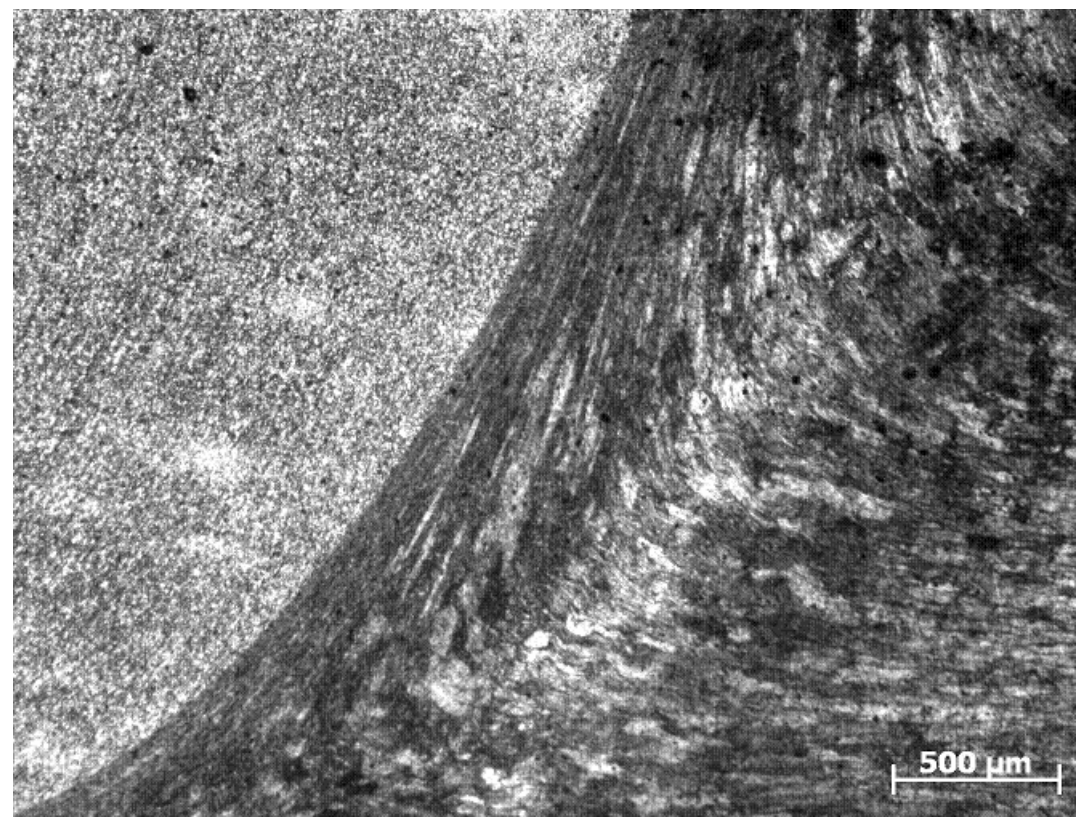

Figure 4 a section of the weld nugget-TMAZ-HAZ interface

The difference between the base material and the nugget grain structure is also shown in Figure 5. The base material in these figures exhibits elongated grain or pancaked type morphology typical of that resulting from cold rolling compared to the fine equiaxed grain of the dynamically recrystallized zone (nugget). 


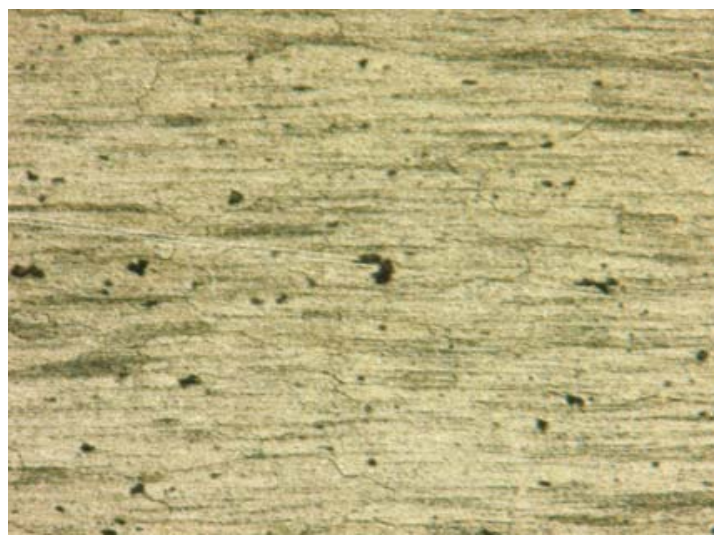

Base material 1000x

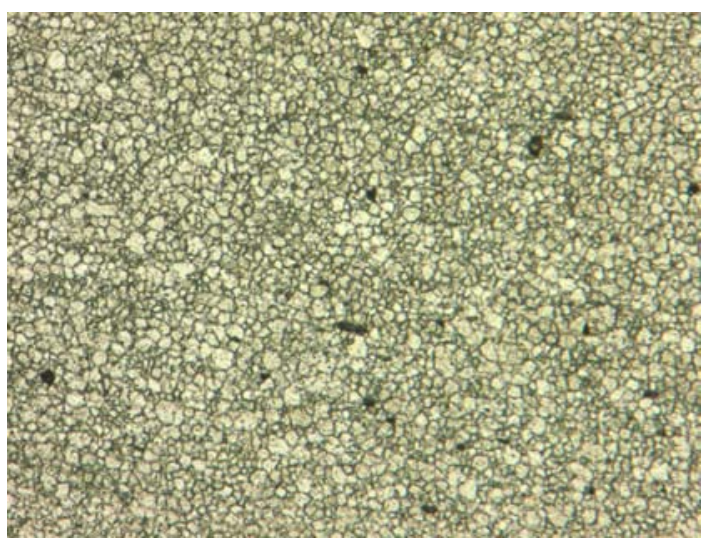

Nugget at $1000 x$

Figure 5. A comparison between the base material and the nugget

\subsection{Microhardness profiles}

To quantify the changes in hardness at different regions across the surface of the weld, Micro-hardness test measurements were taken on the top and bottom surface of the specimens as shown in Figures $6 \& 7$. The measurements were taken using a Struers microhardness machine using a $300 \mathrm{~g}$ for 3 seconds. The figures show a softened region corresponding to the weld nugget. The aluminum alloy sheets which are generally cold rolled tend to increase the mechanical properties of the produced sheets by increasing the dislocation density. As the grains undergo recrystallization in the weld nugget, the strain induced dislocations will annihilate resulting in a decrease to the mechanical properties of the weld.

The soft regions noted throughout the weld could also be attributed to coarsening and dissolution of strengthening precipitates during the thermal cycle of the FSW.

It was noticed that the lowest hardness levels were outside of the weld nugget and close to the edge of the TMAZ. The variations in hardness can be correlated to the microstructure developed after the welding process. Previous work by $[11,12]$ has 
indicated that strengthening precipitates in the HAZ have grown in size and were several times larger than in the parent material, hence resulted in a reduction in hardness. The local coarsening and growth process for strengthening precipitates is a function of temperature, which is a function of distance from the weld nugget [13]. Accordingly, the hardness levels increased with increasing distance from the weld as precipitation hardening became more effective.

Figures $6 \& 7$ indicate that hardening was higher in shot peened specimen compared to laser peened ones. This is consistent with the findings of Peyre et al [14] on unwelded 7075-T7351 aluminum plates. The investigation revealed that Vickers hardness increased from $160 \mathrm{HV}(25 \mathrm{~g})$ to 170 for $7075-\mathrm{T} 7351$ in the laser peened specimens, but Shot peening produces greater surface hardening than laser peening over the first $0.2 \mathrm{~mm}$ from the surface. This was due to differences in the pressure duration produced by the peening process where laser shock interaction times are smaller than those for conventional shot peening. The longer interaction time in the shot peening process results in higher dislocation generation and motion. The higher hardening in shot peening was also attributed to the number of slip planes activated by multiaxial surface loading [15]. The surface hardening in 7075-T7351 caused by laser peening was also demonstrated by Clauer and Fairand [16] who showed that that hardness properties were significantly improved as compared to the unpeened properties. 
Microhardness - Bottom Surface

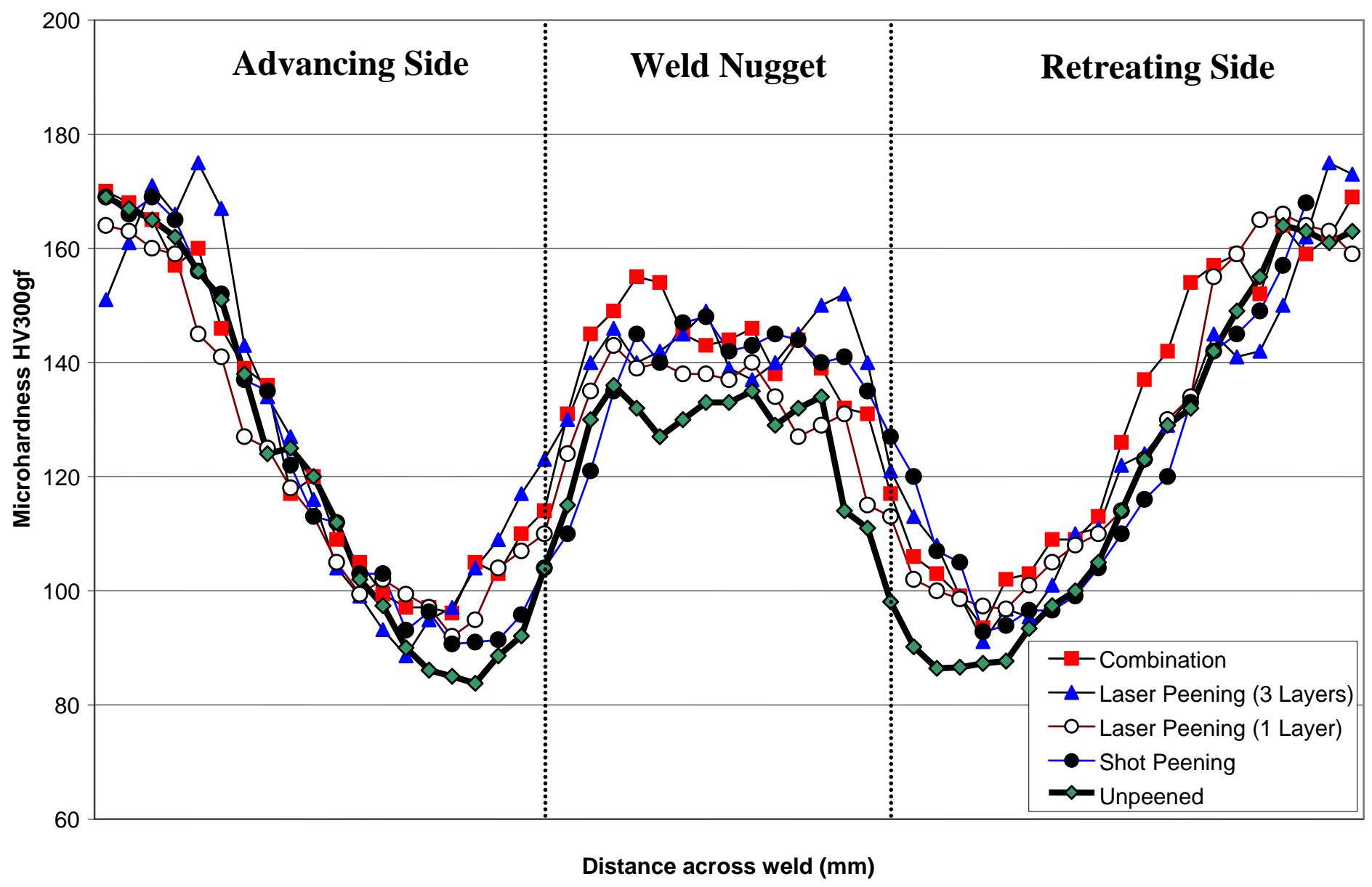

Figure 6 Micro-hardness tests across the bottom surface of FSW 7075-T7351 


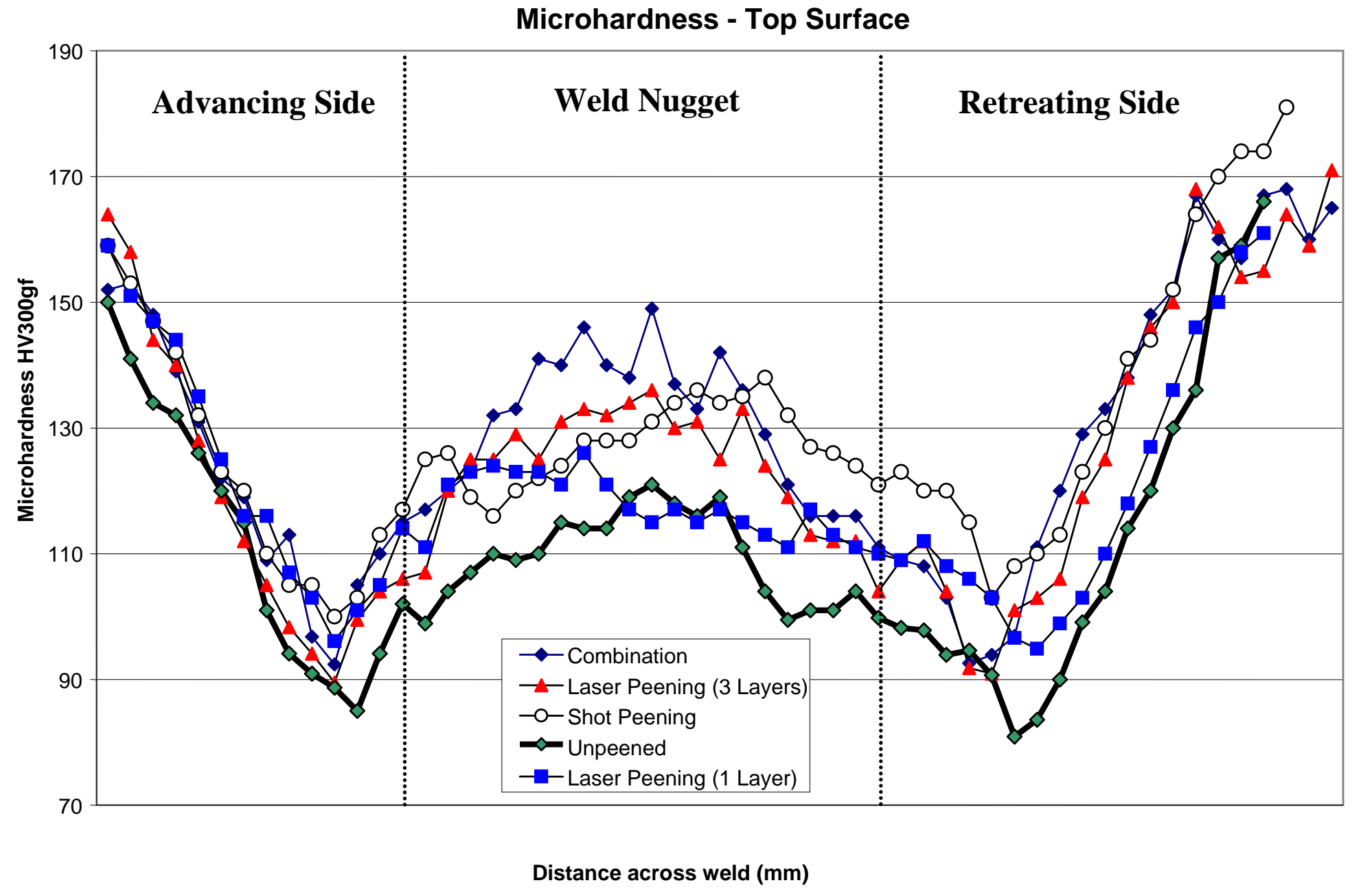

Figure 7 Micro-hardness tests across the top surface of FSW 7075-T7351 
It was also noticed from the hardness profiles that the soften region at the top portion of the weld was relatively wider than the one on the bottom. That is due to the specimen heating characteristics during welding. For example the top region generally exhibits higher temperature compared to the bottom region due to the heating from the tool shoulder, while the bottom surface is in contact with the backing plate which acts as a heat sink. The lower heat input at the bottom can significantly reduce the extent of metallurgical transformations such as re-precipitation and coarsening of precipitates that take place during welding. Therefore, the local strength of individual regions across the weld zone is improved [17]. This is also reflected in Table 1 where the average hardness levels at the weld nugget are represented. The average values on the top region were lower than their correspondent values on the bottom region for the conditions tested. The hardness levels using a single layer of laser peening did not have an effect of the hardness, while using a triple layer resulted in hardness levels comparable to the shot peened ones.

Table 1. Mechanical properties for the various peening configurations

\begin{tabular}{c|cc}
\hline Specimen & $\begin{array}{c}\text { Hardness HV 300 gf } \\
\text { (Top of weld) }\end{array}$ & $\begin{array}{c}\text { Hardness HV 300 gf } \\
\text { (Bottom of weld) }\end{array}$ \\
\hline Unpeened & 117 & 133 \\
Laser Peened (100\%) & 118 & 136 \\
Laser Peened (300\%) & 129 & 143 \\
Shot Peened & 134 & 144 \\
Combination & 136 & 145 \\
\hline
\end{tabular}




\subsection{Mechanical Properties}

The global tensile properties for the different peening configurations are shown in Table 2. While laser peening resulted in a $17 \%$ increase to yield stress, no improvement was obtained to ultimate strength. All tensile specimens fractured at or near the interface between the weld nugget and the TMAZ on the retreating side of the weld at a 45 degree angle. That distance corresponded roughly to the radius of the tool shoulder.

This is normally explained by strain localization within the minimum hardness region of the weld boundary on the retreating side of the weld. This usually happens in areas softened by the welding process which results in a comparatively low overall strain. The interface between the weld nugget and TMAZ correspond to low hardness region because the original structure in this region is over aged and there is not enough solute left in the material. Therefore, this area of the weld will be relatively ineffective in inhibiting dislocation motion and the strain localization in the softened area of the weld will result in a degradation of the mechanical properties. Since the yield strength of the transversely loaded FSW specimens were less than the yield strength of the base metal, the base metal experienced predominantly elastic strain throughout the test [18]. In all cases, mechanical properties for FSW specimens where significantly lower than the base material. 
Table 2. Mechanical properties for the various peening configurations

\begin{tabular}{|c|c|c|c||}
\hline SPECIMEN & $\begin{array}{c}\text { YIELD STRESS } \\
\text { (MPA) }\end{array}$ & $\begin{array}{c}\text { ULTIMATE STRESS } \\
\text { (MPA) }\end{array}$ & $\begin{array}{c}\text { ELONGATION } \\
\text { (\%) }\end{array}$ \\
\hline $\begin{array}{c}\text { Laser Peening } \\
\text { (one layer) }\end{array}$ & 266 & 322 & 4.47 \\
\hline $\begin{array}{c}\text { Laser Peening } \\
\text { (three layers) }\end{array}$ & 266 & 323 & 5.02 \\
\hline $\begin{array}{c}\text { Laser \& Shot } \\
\text { Peening }\end{array}$ & 248 & 320 & 4.47 \\
\hline $\begin{array}{c}\text { Shot Peening } \\
\text { Unpeened }\end{array}$ & 228 & 320 & 4.46 \\
\hline Base & 534 & 319 & 4.57 \\
\hline \hline
\end{tabular}

The consistent failure at the retreating side of the weld also suggests that the intrinsic tensile properties of the welded joints are not symmetric on the two interfaces of the weld. Tensile properties on the retreating side were weaker than the advancing side. Generally the global yield strength in FSW is measured using the $0.2 \%$ offset. This could result in inaccuracies because the strain is not uniform along the gauge length in an under matched weld specimen [2].

Figure 8 shows an example of the mechanical properties at different regions of the weld for a peened specimen. The results were obtained with the aid of strain gages using the iso-stress condition. For the iso-stress condition to be valid the different weld regions are assumed to be arranged in series with a homogeneous cross section at any location in the specimen $[19,20]$. Because of the through the weld thickness property gradients that exists in FSW, this assumption may not be very accurate. 
To verify the iso-stress assumption, Lockwood and Reynolds [20] conducted a series of tensile tests on reduced thickness specimens at different regions across the weld thickness. Overall, the thick specimen properties closely match the thin specimen properties and seem to justify the iso-stress approximation for friction stir welds. It can be seen from the Figure 8 that the lowest properties corresponded to the interface between the weld nugget and the TMAZ. The highest properties in the FSW took place in the nugget region. It was also noticed that the different weld zones resulted in different resistances to deformation due to differences in grain and precipitate size and distribution.

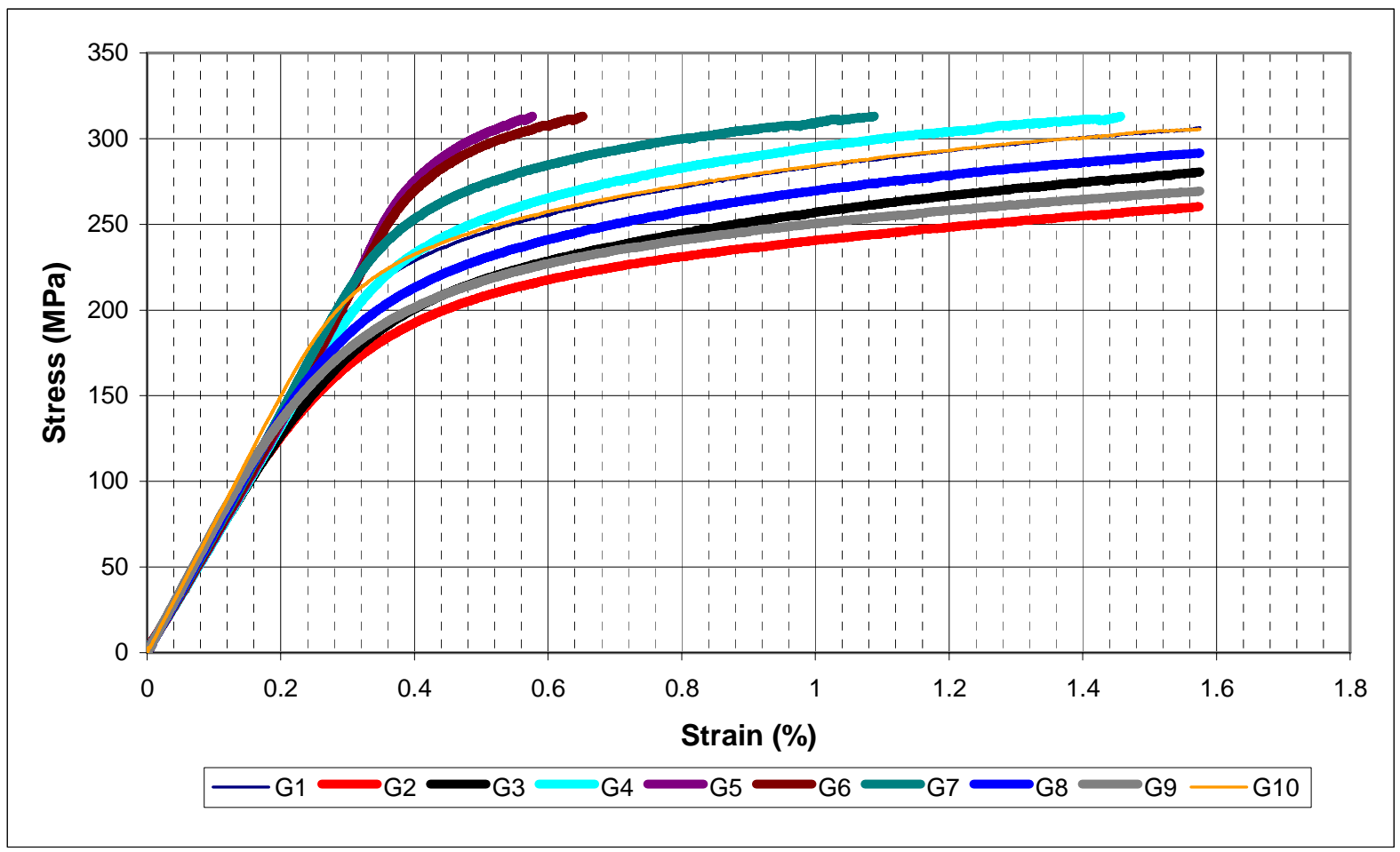

Figure 8 Tensile properties across the weld of a FSW 7075-T7351 
It should be noted that the iso-stress assumption used to determine the local property determination assumes an initially stress free material. Although residual stresses in the unpeened sample were eliminated or greatly reduced by the act of cutting the specimens from the welded plate, substantial residual stresses are expected from the peened specimens. Therefore, the results for the peened specimens may have a higher uncertainty associated with it. Figure 9 represent the tensile properties for different peening methods in the weld nugget region. It is evident that peening the surface resulted in an increase to the yield strength, with the laser peening (300\%) exhibiting the most pronounced effect.

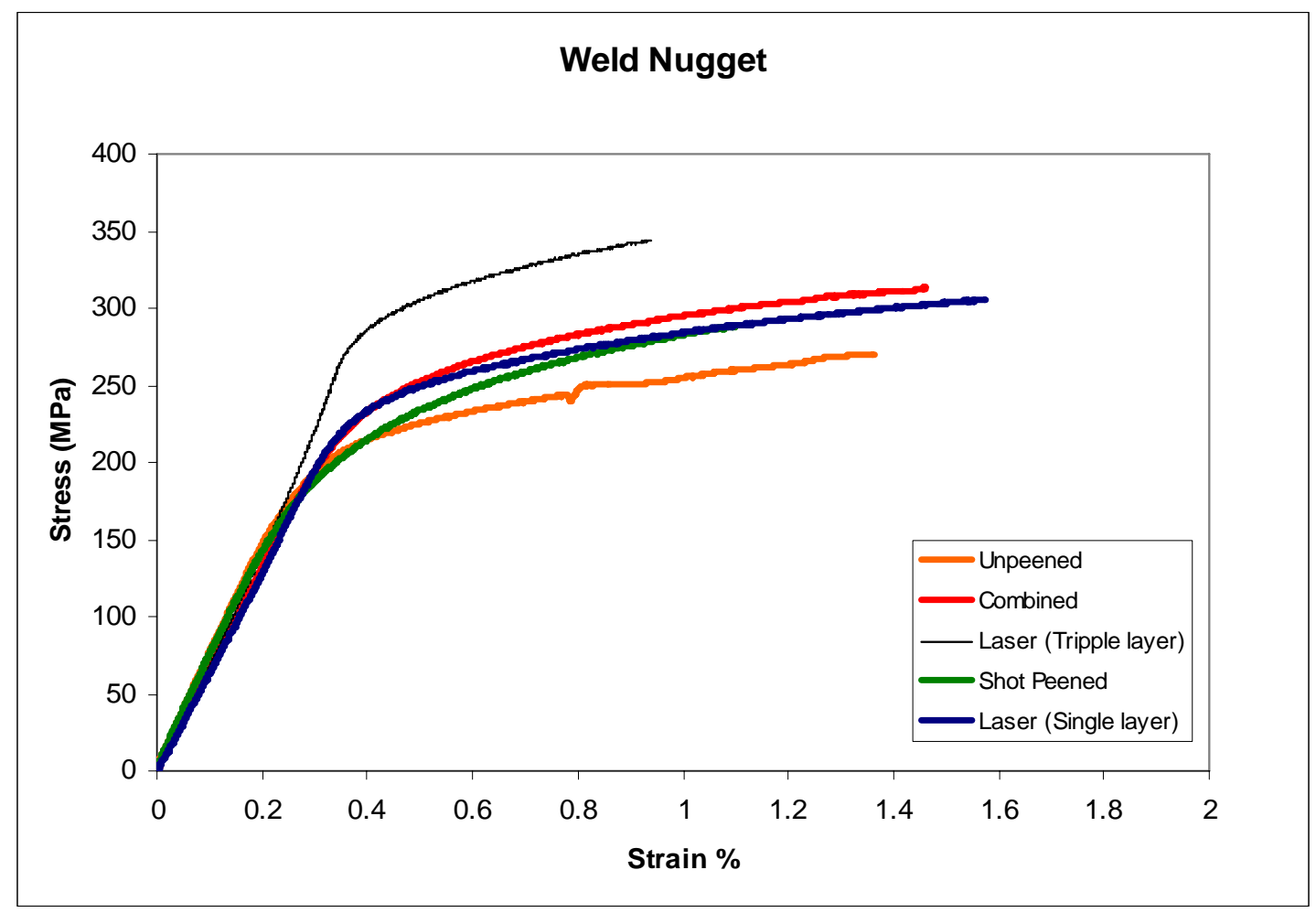

Figure 9 Tensile properties at the weld nugget of a FSW 7075-T7351 
The mechanical properties at the weld interface are represented in Figure 10. This region of the weld resulted in the lowest resistance to plastic deformation due to the microstructure associated with this region as discussed earlier. The results were also compared to the base unwelded material as shown in Figure 11 for comparison. It is evident that significant reduction in strength has resulted from the welding process.

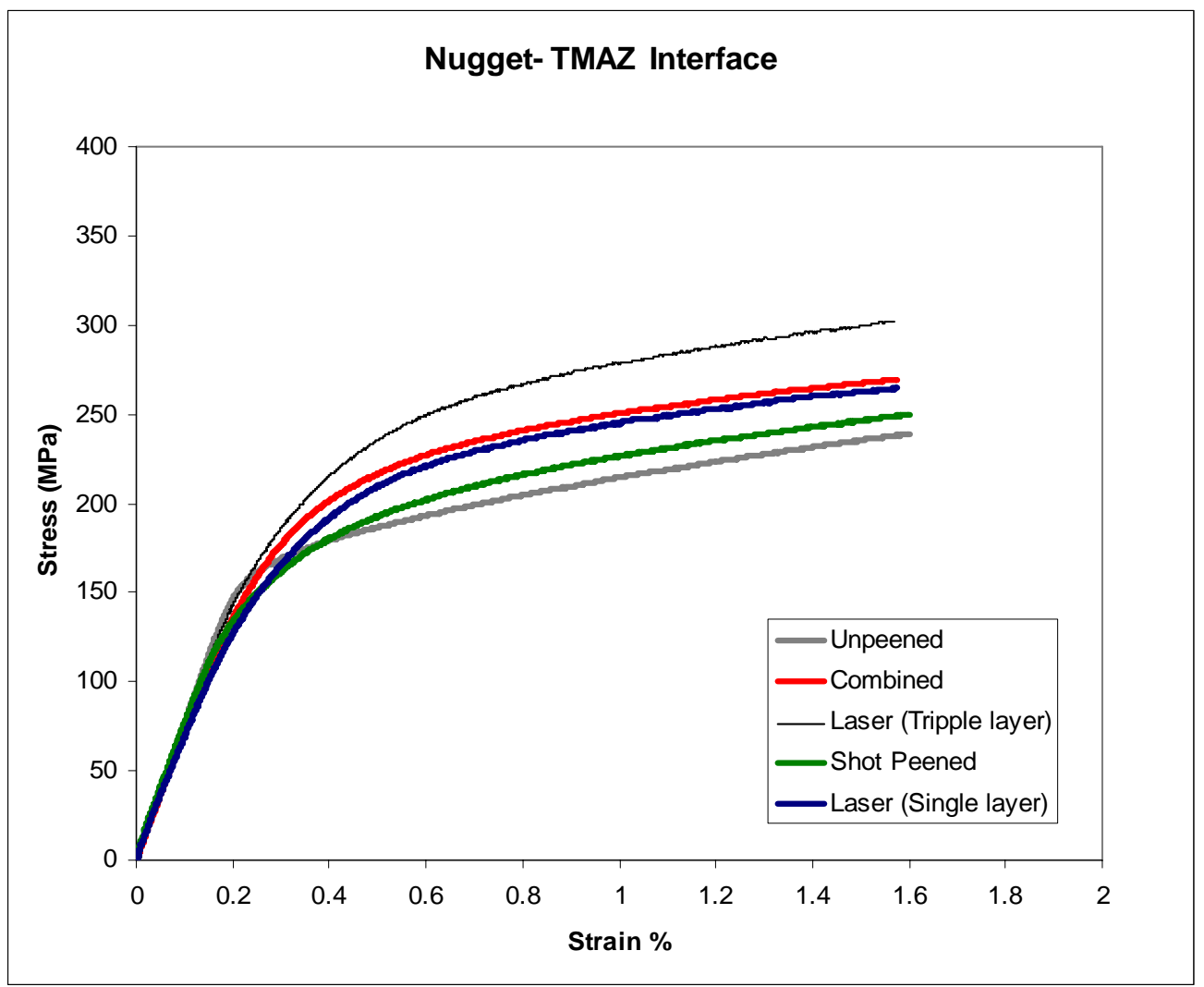

Figure 10 Tensile properties at the nugget-TMAZ interface of a FSW 7075-T7351 


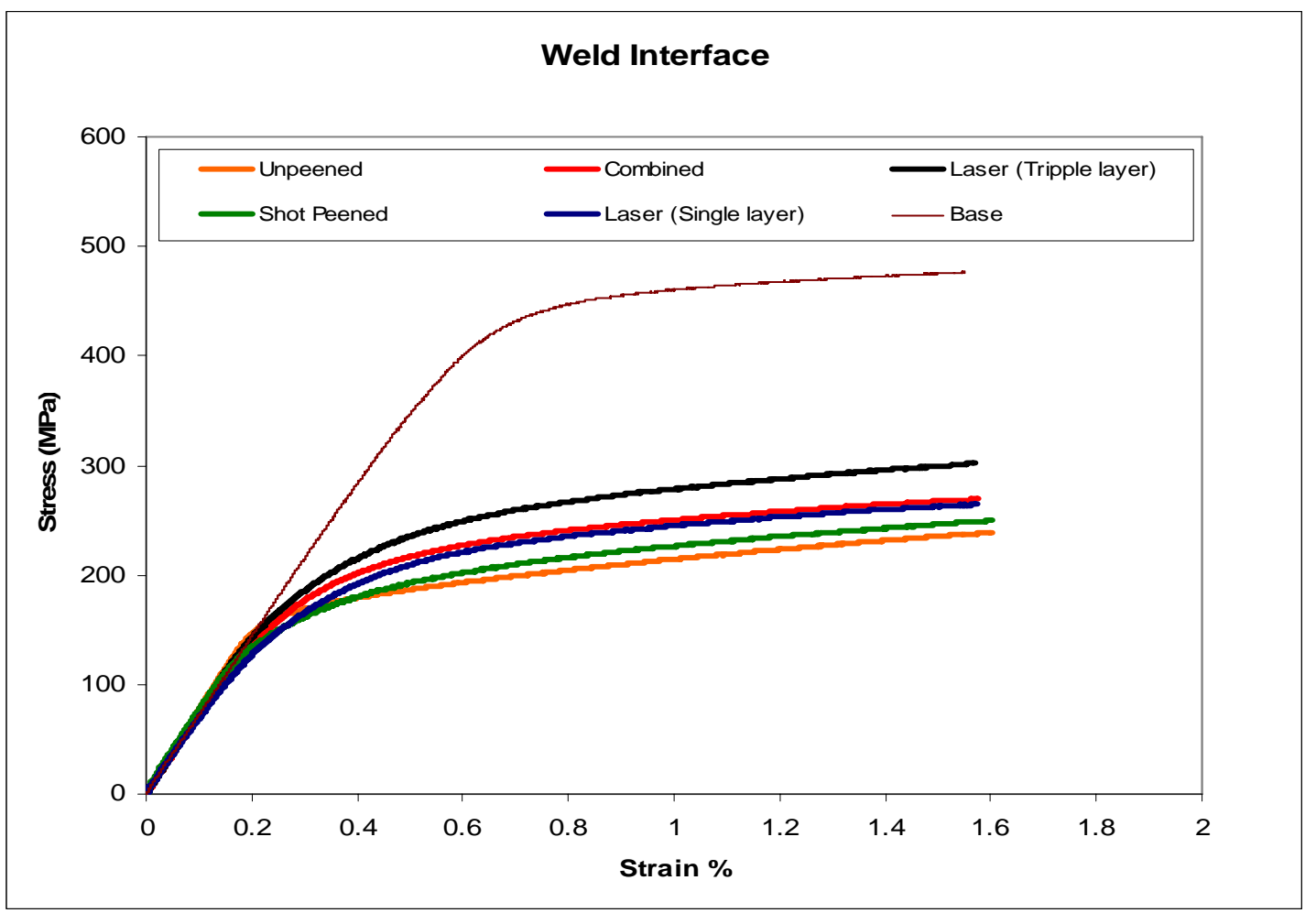

Figure 11 Tensile properties at the nugget-TMAZ interface of a FSW 7075-T7351

Figure 12 illustrates the same effects for the HAZ region. Except for the laser peening using three layers, other peening techniques did not result in a significant increase to tensile properties. The increase in mechanical properties from the laser peening was mainly attributed to the increase in dislocation density by the laser peening process, and the high level of compressive residual stresses introduced during the high energy peening. 


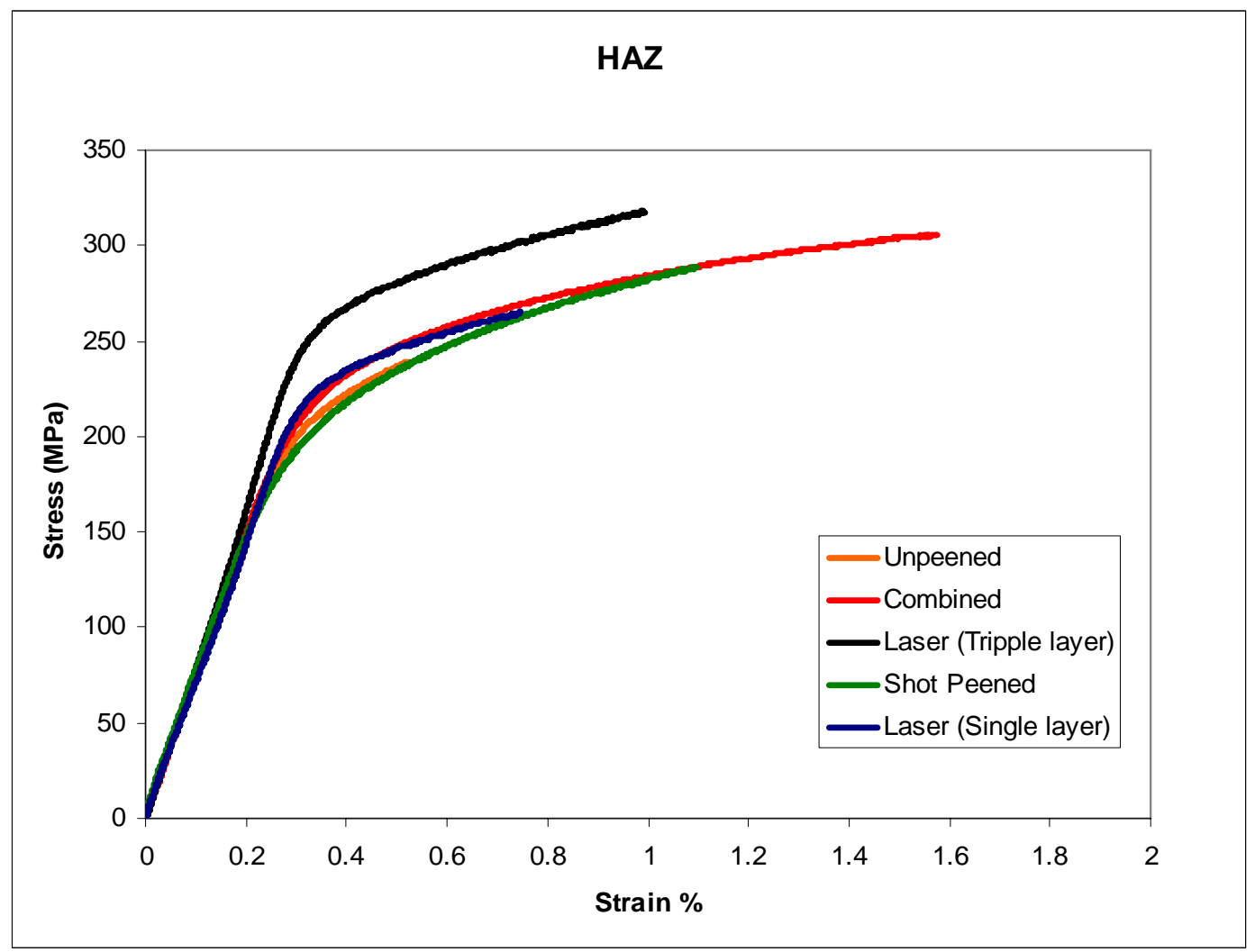

Figure 12 Tensile properties at the HAZ of a FSW 7075-T7351

\subsection{Fractography}

An example of the fractured surface is shown in Figure 13. The microscopically ductile shear fracture took place at 45 degrees by slip along the slip planes that were favorably orientated with respect to the planes of maximum shear stress. Mahoney [13] also attributed the fracture path in FSW to the configuration of the temperature profile through the thickness of the sheet, corresponding to a location where strengthening precipitates were coarsened.

Fractographic examinations of the broken tensile samples revealed characteristic features like dimples indicative of ductile failure. This process takes place in parts containing inclusions or precipitates. Under increased strain microvoids grow, coalescence and finally voids coalesce into a crack until rupture occurs. 


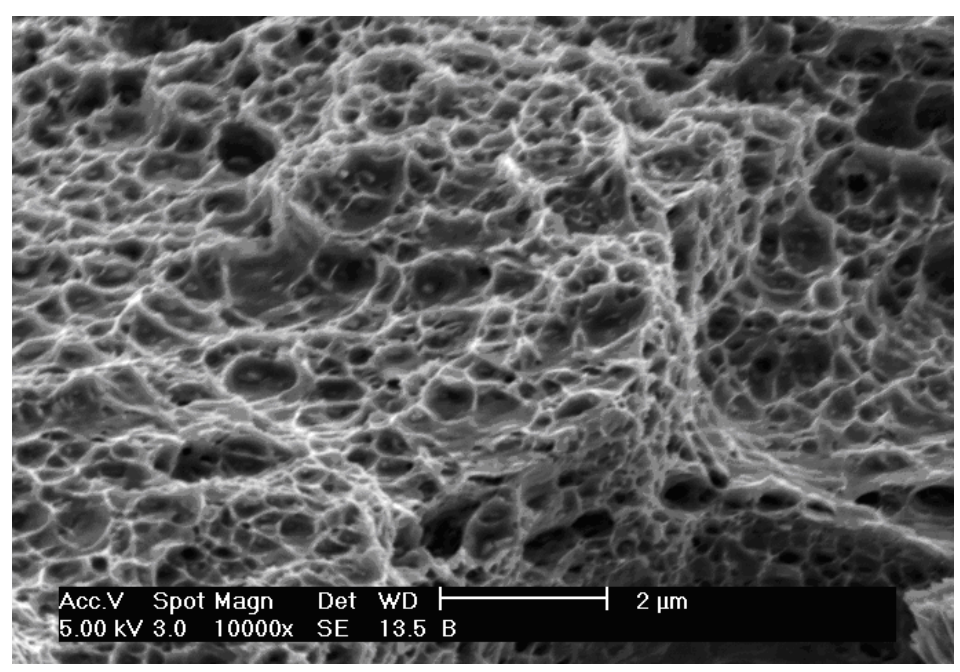

\section{Figure 13 FSW Fracture surface}

\section{$4 \quad$ Summary and Conclusion}

The effects from laser peening, shot peening, and a combination of both on the mechanical properties on Friction Stir Welds AA 7075-T7351 were investigated. The peening effects on the global and local mechanical properties through the different regions of the weld were characterized and assessed. The tensile coupons were machined such as the loading was applied in a direction perpendicular to the weld direction. The surface hardness levels resulting from various peening techniques were also investigated for both sides of the welds. The bottom surface indicated higher hardness levels when compared to the top surface. That was attributed to the lower heat input at the bottom side of the weld, which can significantly reduce the extent of re-precipitation and coarsening of precipitates that take place during welding. Although shot peening resulted in a high increase to hardness it did not improve the tensile properties of the FSW. In contrast, single layer laser peening did not improve the surface hardness but resulted in higher tensile properties. The highest increase in tensile properties resulted from using three layers of laser peening. The increase was mainly attributed to the increase in dislocation density and the high level of compressive residual stresses introduced during the high energy peening. 


\section{References}

1 Thomas W. M et al. Friction stir butt welding. Int Patent App PCT/GB92/02203, and GB Patent App 9125978.8, December 1991. US patent No. 5, 460,317, October 1995

2 Kroninger, H.R, Reynolds, A. P. R-curve behavior of friction stir welds in aluminum-lithium alloy 2195. Fatigue Fract Engineering Mater Struct, (2002) 25, 283-290

3 Sutton, M. A, Reynolds, A. P. et al. A study of residual stresses and microstructure in 2024-T3 aluminum friction stir butt welds. Journal of Engineering Materials and Technology (2002) Vol. 124. 215-221

4 Clauer, A. et al. Metall Transactions. A, 1976, 8, 1871-1876

5 Montross C. et al. Subsurface properties of laser peened 6061-T6 Al weldments. Surface Engineering 2000, Vol. 16, No2. 116-121.

6 John, R., et al. Residual stress effects on near-threshold fatigue crack growth in friction stir welds in aerospace alloys. International Journal of Fatigue 25 (2003) 939-948

7 Mahoney, M. W. et al. Properties of friction -stir-welded 7075 T651 aluminum. Metallurgical and Materials Transactions A. Volume 29A, 1998. pp 1955-1964.

8 Tan Y. et al. Laser shock peening on fatigue crack growth behavior of aluminum alloy. Fatigue and Fracture of Engineering Materials. 27, 649-656.

9 J. K. Gregory, H. J. Rack, and D. Eylon (eds.) Surface Performance of Titanium, TMS, Warrendale, PA. (1996) pp. 217-230

10 Mishra R. S. et al. Friction Stir Welding and Processing. Materials Science and engineering R 50 (2005) 1-78. 
11 Lee, W. et al. Effects of the local microstructures on the mechanical properties in FSWed joints of a 7075-T6 Al alloy. Zeitschrift fuer Metallkunde/Materials Research and Advanced Techniques, v 96, n 8, August, 2005, p 940-947

12 Jata K et al. Metall Materials Transactions. 2000, 31A. 2181-2192.

13 Mahoney M.W. et al. Properties of friction stir welded 7075 T651 aluminum. Metallurgical and Materials Transactions A. Volume 29A (1998) 1955-1964.

14 Peyre P. et al. Laser induced shock waves as surface treatment for 7075-T7351 aluminum alloy. Surface Engineering. Vol 11, No 1 (1995) 47-52

15 Peyre $\mathrm{P}$ et al. Laser shock processing of aluminium alloys. Application to high cycle fatigue behaviour. Materials Science and Engineering A210 (1996) 102-113

16 Fairand B. et al. Laser generates stress waves: their characteristics and their effects on materials. American Institute of Physics Conference. Laser Solid Interactions and Laser Processing. 1978.

17 Lomolino S. et al. On the fatigue behaviour and design curves of friction stir butt-welded Al alloys. International Journal of Fatigue 27 (2005) 305-316

18 Peel M. et al. Microstructure, mechanical properties and residual stresses as a function of welding speed in aluminum AA5083 friction stir welds. Acta Materialia 51 (2003) 4791-4801

19 Lockwood W.D et al. Mechanical response of friction stir welded AA2024: Experiment and modeling. Materials Science and Engineering A, v 323, n 1-2, Jan 31,2002 , p 348-353

20 Lockwood W.D, Reynolds, A.P. Simulation of the global response of a friction stir weld using local constitutive behavior. Materials Science and Engineering A, v 339, n 1-2, Jan 2, 2003, p 35-42 